\title{
Effects of different ways of flower bud differentiation on bud germination and fruit quality of grape
}

\author{
Yan Huang ${ }^{1}$, Bin Hou ${ }^{1}$, Dong Liang ${ }^{1}$, Ronghai $\mathrm{Lu}^{2}$, Lei Liu ${ }^{2}$, Ting Wang ${ }^{2}$, Shaokun Pan ${ }^{2}$ and Xiulan Lv ${ }^{1 *}$ \\ ${ }^{1}$ Institute of Pomology and Olericulture, Sichuan Agricultural University, Chengdu, Sichuan, 611130, China \\ ${ }^{2}$ Chengdu academy of agricultural and forestry sciences, Chengdu, Sichuan, 611130, China
}

\begin{abstract}
Absrtact. In this study, 3 year-old 'Xiahei' grape was used as the test material. It aimed to promote the differentiation of grape flower buds with different concentrations of paclobutrazol and chlormequat chloride, and the effects of different ways of promoting the differentiation of flower buds on the germination of grape buds and fruit quality were studied. The results showed that different ways of flower bud differentiation could promote the germination of 'Xiahei' grape buds. In consideration of the fruiting habit, phenological period and fruit quality of different treatments, second fruits which were sprayed with 1000 times $15 \%$ paclobutrazolin had the best effect. On May 1, 2019 (One fruit sitting period) spraying grape new tip with 1000 times $15 \%$ paclobutrazol and $0.3 \%$ potassium dihydrogen phosphate, $0.1 \%$ boric fertilizer and the same fungicides, spraying again after 7 days, reagent type and concentration were same as the first time, after 10 days of the second spraying $2.5 \%$ hydrogen cyanamide was used to break dormancy of winter bud. The way could effectively promote grape secondary fruit and improve the quality of the grapes.
\end{abstract}

\section{Introduction}

Grape is a plant of grape genus of the family Vitaceae, perennial deciduous vine[1]. It is one of the earliest and most widely distributed fruit trees in the world[2]. Grapes have the characteristics of early fruit, high nutritional value, strong adaptability and quick return on investment. It has become the benefit agriculture of Sichuan, in possession of the majority of farmers love. The ripe period of grape in Sichuan area is different because of variety. However, most of them are concentrated from July to September. Due to the relatively concentrated marketing time and the lack of endurance in storage, the grape is perishable when the sales are not timely, which reduces the economic benefits. Grape secondary fruit can extend the supply period of grape fresh fruit, avoid centralized listing, adjust fresh fruit market off-season supply, it has obvious advantage on price. As a kind of reserve technology, it has a positive effect on making up for the shortage of one time fruit yield.

Studies at home and abroad have shown that plant hormones can affect the flower bud differentiation of grapes [3]. The spray of $1000 \mathrm{mg} / \mathrm{L}$ pletropicazole and $1500 \mathrm{mg} / \mathrm{L}$ tropicol on grape leaves 20 days after the first fruit setting could promote the fruiting of the Manicure finger grape and improve the yield significantly[4]. Seven days before flowering spraying $1300 \mathrm{mg} / \mathrm{L}$ paclobutrazol, pinching 4-5 d before flowering, and then spraying again $7 \mathrm{~d}$ after flowering, could control the growth of secondary shoots, promote flower bud differentiation, and make secondary fruit of secondary shoots of winter buds of Muscat Hamburg grape[5]. At present, domestic and foreign researches on grape mostly focus on balanced fertilization, flower and fruit management and so on, there are few systematic and comprehensive studies on China Agricultural Technology Extension in the middle latitudes. Therefore, this experiment intends to treat and regulate the key links of the secondary fruit of grapes with the early maturing grape 'Xiahei', which is of great commercial value, and comprehensively and systematically study the influence of different ways of flower bud promotion on the secondary fruit of grapes, so as to provide theoretical basis for the secondary fruit of grapes.

\section{Materials and methods}

\subsection{Materials}

Three year-old 'Xiahei'grape with weak or no inflorescence of first fruit was used as the test materials, which had the same tree vigor and management of soil fertilizer and water in Modern agricultural research and development base of Sichuan agricultural university.

\subsection{Experimental design}

During the semi-lignification of $50-70 \mathrm{~cm}$ in the new tip of 'Xiahei' grape, on April 15, 2019, 5-7 leaves were left in the new tip of grape to pinch heavy, while one leaf in

\footnotetext{
*Corresponding author's e-mail: xllvjj@163.com
} 
the auxiliary tip of summer bud was left to pinch, which promoted the differentiation of winner flower bud. In the experiment, two plant growth regulators, paclobutrazol and chlormequat chloride, were used. The concentration level of $15 \%$ paclobutrazol was set at 1000 times, 750 times and 500 times. The concentration level of $50 \%$ chlormequat chloride was set as 1500 times, 1250 times and 1000 times. Water was used as the check. On May 1, 2019 (One fruit sitting period) spraying grape new tip with two plant growth regulators and $0.3 \%$ potassium dihydrogen phosphate, $0.1 \%$ boric fertilizer and the same fungicides, spraying again after 7 days, reagent type and concentration were same as the first time, after 10 days of the second spraying $2.5 \%$ hydrogen cyanamide was used to break dormancy of winter bud, which aimed to promote grape secondary fruit. During the growth of grapes, observing and recording the germination stage, leaf development stage, flowering stage, fruiting stage, turning stage and maturation stage according to the relevant standards of grape phenological period differentiation[6]. The germination rate, branching rate and fruiting rate of different treatments were calculated. Fruit quality of different treatments was determined according to the relevant methods[7-9].

\subsection{Statistical analyses}

The experimental data were processed by Microsoft Excel 2010 software and related charts were drawn. SPSS18.0 software was used for statistical analysis.

\section{Results and Discussion}

\subsection{Comparison of fruiting habits between first and second fruits of grapes}

As could be seen from table 1, the germination rate of 'Xiahei' grape second fruits which were sprayed with 1000 times $15 \%$ paclobutrazolin was the highest, up to $94.0 \%$. Except that there was no significant difference with grape second fruits which were sprayed with 1500 times $50 \%$ chlormequat chloride and first fruit in the germination rate, there was a significant difference in other treatments and the control. The shoot rate and fruit rate of 'Xiahei' grapes which were sprayed with 1000 times $15 \%$ paclobutrazolin and 1500 times $50 \%$ chlormequat chloride was the highest, it had no significant difference with first fruit, but it was significantly higher than those of other treatments and control, the branch rate was up to $95.8 \%$ and $90.5 \%$ respectively, increasing by $80.0 \%$ and $78.9 \%$ in comparison with the control respectively. There was no significant difference in fruit setting rate between the first and second fruits. To sum up, the germination rate, shoot rate and fruiting rate of grapes which were sprayed with 1000 times $15 \%$ paclobutrazolin and 1500 times $50 \%$ chlormequat chloride were high, which showed that the fruit habit was good.

Table 1. Comparison of the growth and fruiting characteristics between the first and second grape.

\begin{tabular}{ccccc}
\hline Treatments & $\begin{array}{c}\text { Germination rate } \\
(\%)\end{array}$ & $\begin{array}{c}\text { Shoot rate } \\
(\%)\end{array}$ & $\begin{array}{c}\text { Fruit rate } \\
(\%)\end{array}$ & $\begin{array}{c}\text { Setting rate } \\
(\%)\end{array}$ \\
\hline 1000 times 15\% paclobutrazol & $94.0 \mathrm{a}$ & $95.8 \mathrm{a}$ & $93.1 \mathrm{a}$ & $45.3 \mathrm{a}$ \\
750 times 15\% paclobutrazol & $87.5 \mathrm{~b}$ & $87.5 \mathrm{~b}$ & $67.1 \mathrm{~b}$ & $38.2 \mathrm{a}$ \\
500 times 15\% paclobutrazol & $79.2 \mathrm{c}$ & $83.3 \mathrm{~b}$ & $39.4 \mathrm{c}$ & $36.9 \mathrm{a}$ \\
1500 times 50\% chlormequat chloride & $92.8 \mathrm{a}$ & $90.5 \mathrm{a}$ & $93.7 \mathrm{a}$ & $39.5 \mathrm{a}$ \\
1250 times 50\% chlormequat chloride & $81.3 \mathrm{~b}$ & $81.2 \mathrm{~b}$ & $75.8 \mathrm{~b}$ & $37.6 \mathrm{a}$ \\
1000 times 50\% chlormequat chloride & $71.3 \mathrm{c}$ & $79.2 \mathrm{~b}$ & $46.9 \mathrm{c}$ & $36.6 \mathrm{a}$ \\
Water & $23.5 \mathrm{~d}$ & $19.1 \mathrm{~d}$ & $0 \mathrm{~d}$ & $/$ \\
Frist fruit & $92.5 \mathrm{a}$ & $92.0 \mathrm{a}$ & $96.4 \mathrm{a}$ & $39.6 \mathrm{a}$ \\
\hline
\end{tabular}

Note: In the table, the lowercase letters indicate the level of significance of difference at $\mathrm{P}=0.05$, the below is same.

\subsection{Phenological observation on the first and second fruits of grape}

It could be seen from table 2 that different flower bud promotion methods all promoted the germination of grape winter buds. Grapes which were sprayed with 1000 times $15 \%$ paclobutrazolin and 1500 times $50 \%$ chlormequat chloride had better effects. The first fruit germination period of 'Xiahei' grape was from March 5 to March 9, the flowering period was from April 8 to April 23, and the fruit ripening period was from July 2 to July 10 . The germination period of second fruit which was sprayed with 1000 times $15 \%$ paclobutrazolin was from June 2 to June 5, the flowering period was June 24 to July 3, and the fruit ripening period was September 13 to September 20. The fruit ripening period was similar to that of the second fruit which was sprayed with 1500 times $50 \%$ chlormequat chloride. Compared with other treatments, the fruit ripening period was 7 to 15 days earlier, and the fruit ripening period was 72 to 73 days later than that of the first fruit. In summary, China Agricultural Technology Extension was beneficial to avoid grape concentration of listed and increase its economic benefit. 
Table 2. The phenological period of the first and second grape (m.d).

\begin{tabular}{ccccccc}
\hline Treatments & $\begin{array}{c}\text { germination } \\
\text { period }\end{array}$ & $\begin{array}{c}\text { Exhibition } \\
\text { leaf period }\end{array}$ & $\begin{array}{c}\text { Flowering } \\
\text { period }\end{array}$ & $\begin{array}{c}\text { Sitting } \\
\text { period }\end{array}$ & $\begin{array}{c}\text { Veraison } \\
\text { period }\end{array}$ & $\begin{array}{c}\text { Mature } \\
\text { period }\end{array}$ \\
\hline 1000 times 15\% paclobutrazol & $6.2 \sim 6.5$ & $6.10 \sim 6.14$ & $6.24 \sim 7.3$ & $7.8 \sim 7.14$ & $7.25 \sim 8.25$ & $9.13 \sim 9.20$ \\
750 times 15\% paclobutrazol & $6.7 \sim 6.10$ & $6.14 \sim 6.19$ & $7.1 \sim 7.10$ & $7.14 \sim 7.20$ & $8.1 \sim 8.30$ & $9.20 \sim 9.29$ \\
500 times 15\% paclobutrazol & $6.13 \sim 6.17$ & $6.21 \sim 6.26$ & $7.3 \sim 7.12$ & $7.16 \sim 7.21$ & $8.7 \sim 9.5$ & $9.23 \sim 10.4$ \\
1500 times 50\% chlormequat chloride & $6.3 \sim 6.6$ & $6.11 \sim 6.16$ & $6.25 \sim 7.4$ & $7.8 \sim 7.16$ & $7.28 \sim 8.27$ & $9.15 \sim 9.20$ \\
1250 times 50\% chlormequat chloride & $6.9 \sim 6.11$ & $6.14 \sim 6.20$ & $7.2 \sim 7.9$ & $7.16 \sim 7.21$ & $8.5 \sim 8.29$ & $9.23 \sim 10.1$ \\
1000 times 50\% chlormequat chloride & $6.16 \sim 6.20$ & $6.23 \sim 6.28$ & $7.5 \sim 7.14$ & $7.20 \sim 7.25$ & $8.9 \sim 9.8$ & $9.26 \sim 10.5$ \\
Water & $/$ & $/$ & $/$ & $/$ & $/$ & $/$ \\
Frist fruit & $3.5 \sim 3.9$ & $3.20 \sim 3.25$ & $4.8 \sim 4.23$ & $4.28 \sim 5.5$ & $5.18 \sim 6.17$ & $7.2 \sim 7.10$ \\
\hline
\end{tabular}

\subsection{Comparison of fruit quality between first and second fruits of grape}

As could be seen from table 3, the single ear weight and single fruit weight of the second fruits which were sprayed with 1000 times $15 \%$ paclobutrazolin were significantly higher than that of the other treatments of the second fruit. And they were lower than that of the first fruit, but there were no significant difference compared with the first fruit. There was no significant difference in ear length, ear width, longitudinal diameter, transverse diameter and shape index between the different treatments of second fruits and first fruits. The fruits of each treatment, control and first fruit were all purple and black, and the color uniformity was consistent

According to table 4, there was no significant difference in the fruit hardness and soluble solids between the different treatments of second fruits, but both were significantly higher than the fruit hardness and soluble solids of the first fruit.The reductive sugar of second fruits which were sprayed with 1000 times $15 \%$ paclobutrazolin was the highest, up to $16.23 \mathrm{~g} / 100 \mathrm{~mL}$, which was $13.74 \%$ higher than that of first fruits. The titrable acid was also the highest, up to $0.75 \mathrm{~g} / 100 \mathrm{~mL}$, which was $30.67 \%$ higher than that of first fruit. There was no significant difference in Vc content between the different treatments of second fruits and first fruits.In conclusion, second fruits which were sprayed with 1000 times $15 \%$ paclobutrazolin had the best fruit quality.

Table 3. Comparison of the external quality between the first and second fruit.

\begin{tabular}{cccccccc}
\hline Treatments & $\begin{array}{c}\text { Ear } \\
\text { weight } \\
(\mathrm{g})\end{array}$ & $\begin{array}{c}\text { Ear length } \\
(\mathrm{cm})\end{array}$ & $\begin{array}{c}\text { Ear width } \\
(\mathrm{cm})\end{array}$ & $\begin{array}{c}\text { Fruit } \\
\text { weight } \\
(\mathrm{g})\end{array}$ & $\begin{array}{c}\text { Longitudinal } \\
\text { diameter } \\
(\mathrm{cm})\end{array}$ & $\begin{array}{c}\text { Transverse } \\
\text { diameter } \\
(\mathrm{cm})\end{array}$ & $\begin{array}{c}\text { Shape } \\
\text { index }\end{array}$ \\
\hline $\begin{array}{c}1000 \text { times } 15 \% \\
\text { paclobutrazol }\end{array}$ & $518.3 \mathrm{a}$ & $21.5 \mathrm{a}$ & $11.5 \mathrm{a}$ & $4.57 \mathrm{a}$ & $2.05 \mathrm{a}$ & $1.95 \mathrm{a}$ & $1.05 \mathrm{a}$ \\
$\begin{array}{c}750 \text { times } 15 \% \\
\text { paclobutrazol }\end{array}$ & $382.5 \mathrm{~b}$ & $22.8 \mathrm{a}$ & $12.6 \mathrm{a}$ & $4.00 \mathrm{~b}$ & $1.96 \mathrm{a}$ & $1.83 \mathrm{a}$ & $1.07 \mathrm{a}$ \\
$\begin{array}{c}500 \text { times } 15 \% \\
\text { paclobutrazol }\end{array}$ & $383.3 \mathrm{~b}$ & $22.0 \mathrm{a}$ & $12.0 \mathrm{a}$ & $3.86 \mathrm{~b}$ & $1.94 \mathrm{a}$ & $1.89 \mathrm{a}$ & $1.04 \mathrm{a}$ \\
$\begin{array}{c}1500 \text { times } 50 \% \\
\text { chlormequat } \\
\text { chloride }\end{array}$ & $405.2 \mathrm{~b}$ & $21.6 \mathrm{a}$ & $11.9 \mathrm{a}$ & $3.81 \mathrm{~b}$ & $2.05 \mathrm{a}$ & $1.87 \mathrm{a}$ & $1.10 \mathrm{a}$ \\
$\begin{array}{c}1250 \text { times } 50 \% \\
\text { chlormequat } \\
\text { chloride }\end{array}$ & $379.2 \mathrm{~b}$ & $21.8 \mathrm{a}$ & $11.8 \mathrm{a}$ & $4.15 \mathrm{~b}$ & $2.04 \mathrm{a}$ & $1.95 \mathrm{a}$ & $1.05 \mathrm{a}$ \\
$\begin{array}{c}1000 \text { times } 50 \% \\
\text { chlormequat } \\
\text { chloride }\end{array}$ & $398.6 \mathrm{~b}$ & $22.4 \mathrm{a}$ & $12.4 \mathrm{a}$ & $3.96 \mathrm{~b}$ & $1.94 \mathrm{a}$ & $1.90 \mathrm{a}$ & $1.00 \mathrm{a}$ \\
$\begin{array}{c}\text { Water } \\
\text { First fruit }\end{array}$ & $644.3 \mathrm{a}$ & $24.0 \mathrm{a}$ & $12.0 \mathrm{a}$ & $4.84 \mathrm{a}$ & $2.10 \mathrm{a}$ & $2.00 \mathrm{a}$ & $1.05 \mathrm{a}$ \\
\hline
\end{tabular}

Table 4. Comparison of the intrinsic quality between the first and second fruit.

\begin{tabular}{cccccc}
\hline Treatments & $\begin{array}{c}\text { Fruit hardness } \\
\left.(\mathrm{kgf.cm})^{-2}\right)\end{array}$ & $\begin{array}{c}\text { Soluble solids } \\
(\%)\end{array}$ & $\begin{array}{c}\text { Reductive sugar } \\
(\mathrm{g} / 100 \mathrm{~mL})\end{array}$ & $\begin{array}{c}\text { Titrable acid } \\
(\mathrm{g} / 100 \mathrm{~mL})\end{array}$ & $\begin{array}{c}\text { Vc content } \\
(\mathrm{mg} / 100 \mathrm{~mL})\end{array}$ \\
\hline $\begin{array}{c}1000 \text { times } 15 \% \\
\text { paclobutrazol }\end{array}$ & $5.58 \mathrm{a}$ & $23.1 \mathrm{a}$ & $16.23 \mathrm{a}$ & $0.75 \mathrm{a}$ & $3.51 \mathrm{a}$ \\
$\begin{array}{c}750 \text { times } 15 \% \\
\text { paclobutrazol }\end{array}$ & $5.70 \mathrm{a}$ & $22.0 \mathrm{a}$ & $15.69 \mathrm{a}$ & $0.61 \mathrm{a}$ & $2.80 \mathrm{a}$ \\
$\begin{array}{c}500 \text { times } 15 \% \\
\text { paclobutrazol }\end{array}$ & $5.19 \mathrm{a}$ & $20.8 \mathrm{a}$ & $14.60 \mathrm{~b}$ & $0.52 \mathrm{~b}$ & $2.70 \mathrm{a}$ \\
$\begin{array}{c}1500 \text { times } 50 \% \\
\text { chlormequat chloride }\end{array}$ & $5.50 \mathrm{a}$ & $22.5 \mathrm{a}$ & $16.18 \mathrm{a}$ & $0.59 \mathrm{~b}$ & $2.98 \mathrm{a}$
\end{tabular}




\begin{tabular}{cccccc}
$\begin{array}{c}1250 \text { times } 50 \% \\
\text { chlormequat chloride }\end{array}$ & $5.42 \mathrm{a}$ & $21.2 \mathrm{a}$ & $15.71 \mathrm{a}$ & $0.56 \mathrm{~b}$ & $3.02 \mathrm{a}$ \\
$\begin{array}{c}1000 \text { times } 50 \% \\
\text { chlormequat chloride }\end{array}$ & $5.21 \mathrm{a}$ & $20.6 \mathrm{a}$ & $14.48 \mathrm{~b}$ & $0.49 \mathrm{~b}$ & $2.82 \mathrm{a}$ \\
$\begin{array}{c}\text { Water } \\
\text { Frist fruit }\end{array}$ & $/$ & $/$ & $/$ & $/$ & $/$ \\
\hline
\end{tabular}

\section{Conclusions}

The results showed that different ways of flower bud differentiation could promote the germination of 'Xiahei' grape buds. In consideration of the fruiting habit, phenological period and fruit quality of different treatments, second fruits which were sprayed with 1000 times $15 \%$ paclobutrazolin had the best effect. On May 1, 2019 (One fruit sitting period) spraying grape new tip with 1000 times $15 \%$ paclobutrazol and $0.3 \%$ potassium dihydrogen phosphate, $0.1 \%$ boric fertilizer and the same fungicides. Spraying again after 7 days, reagent type and concentration were same as the first time. After 10 days of the second spraying $2.5 \%$ hydrogen cyanamide was used to break dormancy of winter bud. The way could effectively promote grape secondary fruit and improve the quality of the grapes.

\section{Acknowledgements}

This work was financially supported by the application foundation project of Sichuan Science and Technology Department (2018JY0374).

\section{References}

1. Kong Q.S. (2005) Acta fruticae sinica, Grape records of China. 22: 334.

2. Wang F.C. (2013) Effect of sulfur dioxide treatment on postharvest diseases and physiology of table grapes storage, Thesis for M.S., Xinjiang Agricultural University, 1-2.

3. Ma H.P. (1987) Relationship between flower bud differentiation and hormones in fruit trees, Plant physiology communications, 1: 1 .

4. Li D.F, Liu J.Y, Feng J.X. (2001) The secondary result test was carried out by using grape fruiting twigs, Fruit trees of south China, 40: 79-81.

5. Xu Z.H. (2011) Second fruit cultivation technique of hutai no. 8 grape. Modern horticulture, 13: 38.

6. Liang L.F. (2001) Experimental practice guidance of fruit tree cultivation, China Agriculture Press, Beijing, China, 19-20.

7. Huang X.Y., Liu L.W. (2009) Experiments of food chemistry and comprehensive analysis, China Agricultural University press, Beijing, China, 153-154.

8. Lin H.H., Zhao Y. (2003) Basic experimental instruction of modern biology, Sichuan University Press, Chengdu, China, 240-241.
9. Wang Y.D., Liu N. (2011) Plant biology experiment guide, Higher Education Press, Beijing, China, 60-61. 